\title{
PERCEPÇÃO AMBIENTAL: ESTUDO DE CASO SOBRE COLETA SELETIVA NA COMUNIDADE ACADÊMICA DA UNIVERSIDADE FEDERAL RURAL DA AMAZÔNIA
}

\author{
Gustavo Francesco de Morais Dias ${ }^{1}$, Tássia Toyoi Gomes Takashima-Oliveira ${ }^{2}$, \\ Giovani Rezende Barbosa Ferreira ${ }^{3}$, Marcos Alexandre Lopes Pantoja ${ }^{4}$, Pedro \\ Silvestre da Silva Campos ${ }^{5}$. \\ ${ }^{1}$ Mestrando em Ciências Ambientais da Universidade Federal do Pará, Belém-PA, \\ Brasil (gustavo_dias01@hotmail.com) \\ ${ }^{2}$ Mestranda em Ciências Ambientais da Universidade do Estado do Pará, Belém-PA, \\ Brasil \\ ${ }^{3}$ Mestrando em Ciências Ambientais da Universidade Federal do Pará, Belém-PA, \\ Brasil \\ ${ }^{4}$ Engenheiro Ambiental e Energias Renováveis, Belém-PA, Brasil \\ ${ }^{5}$ Professor Doutor da Universidade Federal Rural da Amazônia, Belém-PA, Brasil \\ Recebido em: 02/10/2017 - Aprovado em: 21/11/2017 - Publicado em: 05/12/2017 \\ DOI: 10.18677/EnciBio_2017B106
}

\begin{abstract}
RESUMO
Diante dos impactos gerados pelo aumento da produção e destinação inadequada de resíduos sólidos urbanos, a coleta seletiva consiste em uma estratégia primordial voltada para amenizar esses prejuízos. O objetivo deste trabalho foi analisar a percepção da comunidade acadêmica da UFRA campus Belém sobre a Coleta Seletiva. Para coleta de dados, utilizou-se um questionário fechado, composto por 13 perguntas. Percebeu-se que quando se trata de tópicos específicos, como relacionar o tipo de resíduo gerado com a cor do recipiente para ser condicionado ou discernir os resíduos recicláveis e os não recicláveis ou conhecer qual a finalidade do Programa de Coleta Seletiva Solidária, observou-se que a proporção de alunos que desconhecem esses eixos aumentou entre $6 \%$ a $81 \%$ com relação ao ínfimo grupo que desconhece o que é coleta seletiva (2,7\%). Os graduandos dos cursos de Licenciatura da Computação e Sistema de Informação compreenderam a proporção de alunos que mais desconhecem as temáticas referente a coleta seletiva. A insuficiência do número de lixeiras seletivas agregada às poucas ações de educação de sensibilização, favorece o condicionamento dos resíduos gerados pelos discentes em lixeiras comuns (63\%), mesmo que $90 \%$ dos entrevistados tenham alegado em segregar adequadamente os resíduos caso a universidade formalizasse parceria com cooperativas para coleta desse material. Conclui-se que a percepção dos discentes da UFRA ainda é limitada no aspecto geral do conceito de coleta seletiva, o que implica na falta de sensibilidade sobre seu papel diante dos impactos gerados pelo inadequado condicionamento dos resíduos.
\end{abstract}

PALAVRAS-CHAVE: Ensino superior, lixeiras seletivas, resíduos sólidos. 


\title{
ENVIRONMENTAL PERCEPTION: CASE STUDY ON SELECTIVE COLLECTION IN THE ACADEMIC COMMUNITY IN THE UNIVERSIDADE FEDERAL RURAL DA AMAZÔNIA
}

\begin{abstract}
In view of the impacts generated by increased production and inadequate disposal of urban solid waste, selecting collection is a primordial strategy aimed at mitigating these losses. The objective of this work was to analyze the perception of the academic community of the UFRA Campus Belém about Selective Collection Waste. For data collection, a closed questionnaire was used, composed of 13 questions. It was noticed that when it comes to specific topics, such as relating the type of waste generated with the color of the container to be conditioned or to discern recyclable and non-recyclable waste or to know the purpose of the Selective Solidarity Collection Program, it was observed that the ratio of students who do not know these concepts increased from $6 \%$ to $81 \%$ in relation to the smallest group that does not know what selective collection is (2.7\%). The graduates of Computer Science and Information System courses are the portion of students who are most ignorant of the issues about the selective collection. The insufficiency of selective dumps added to the few actions of raising awareness trigger placing the waste generated by the students in common dumps (63\%), even though $90 \%$ of the interviewees claimed to segregate the waste properly if the university formalized a partnership with cooperatives to collect this material. It is concluded that UFRA students' perceptions are still limited in the general aspect of the concept of selective collection waste, which implies a lack of sensitivity regarding their role in the impacts generated by inadequate waste conditioning.
\end{abstract}

KEYWORDS: Higher education, selective dumps, solid waste.

\section{INTRODUÇÃO}

A preocupação em relação aos resíduos sólidos tem aumentado constantemente nos últimos anos, principalmente devido ao crescimento da produção de insumos e à falta de áreas adequadas para a disposição final. $O$ assunto mostrou-se prioritário em escala mundial desde a Conferência das Nações Unidas sobre o Ambiente e o Desenvolvimento (Rio-92), tanto nos países desenvolvidos, como nos em desenvolvimento (BESEN et al., 2014).

No Brasil encontra-se um cenário assustador em relação ao gerenciamento dos resíduos sólidos, cabe aos governantes com a participação popular tomar iniciativas em prol do combate a esse gerenciamento inadequado que ocasiona diversos prejuízos a sociedade há várias décadas. A gestão inadequada dos resíduos sólidos e a excessiva produção, provocam inúmeras doenças, problemas sanitários, assoreamento dos rios, entupimento de bueiros, contaminação do ar e solo, entre outros (LEITE et al., 2015).

Nesse contexto, a coleta seletiva dos resíduos sólidos surge como uma das possíveis soluções para a suavização dos impactos ambientais ocasionados pelo excesso de lixo, essa medida busca reciclar materiais como papéis, vidros, metais e plásticos, todos previamente separados pelas fontes geradoras. A segregação dos resíduos é fundamental para que a coleta seletiva seja otimizada e eficiente. Além disso a reciclagem é muito importante pois promove benefícios, como: diminuição da exploração dos recursos naturais; economia de energia; melhoria da qualidade de 
vida ambiental; geração de emprego e renda; diminuição da disposição do lixo nos aterros; menor impacto no meio ambiente e entre outros (CORREA, 2012).

A Política Nacional de Resíduos Sólidos (PNRS), sancionada pela Lei $\mathrm{n}^{\circ}$. 12.305/2010 (BRASIL, 2010), destaca a importância do gerenciamento adequado dos resíduos sólidos desde a geração até o destino final, a responsabilidade pelo gerenciamento adequado dos resíduos sólidos fica a cargo dos municípios e dos geradores, a PNRS também ressalta a importância da etapa da coleta seletiva e da reciclagem (BELUQUE, 2015). Nesse sentido, a política afirma que a coleta seletiva deve ser considerada nos planos de âmbito regional, e que devem ser criados instrumentos econômicos para a implementação (OLIVEIRA; JUNIOR, 2016).

A Coleta seletiva deve ser vista como uma corrente de três elos. Se um destes não for planejado a tendência é o programa de coleta seletiva não perseverar. O planejamento deve ser feito do fim para o começo da cadeia. Ou seja: primeiro pensar em qual será a destinação, depois a logística e por fim o programa de educação ambiental (SOUZA, 2014). Na perspectiva atual, a coleta seletiva não deve ser vista de forma isolada, mas, sim, como parte de uma gestão integrada que envolve coleta, transporte, tratamento e destinação final dos resíduos sólidos domésticos em aterros sanitários (EIGENHEER; FERREIRA, 2015).

A Universidade Federal Rural da Amazônia - UFRA vem gradativamente implantando o Programa de Coleta Seletiva de Resíduos Sólidos nas suas unidades, conforme disposto no Decreto Federal 5.940/2006 (BRASIL, 2006) que institui a coleta seletiva nas Instituições Públicas Federais, porém a universidade ainda não instituiu a Coleta Seletiva Solidária que consiste na destinação dos materiais recicláveis às associações e cooperativas de catadores.

Dentro desse contexto, o objetivo deste trabalho foi analisar a percepção da comunidade acadêmica da UFRA campus de Belém acerca da Coleta Seletiva em âmbito universitário.

\section{MATERIAL E MÉTODOS}

O presente estudo foi desenvolvido na Universidade Federal Rural da Amazônia-UFRA (Figura 1), localizada em Belém-PA, durante os meses de janeiro e maio de 2016. O campus de Belém atende a 2.379 discentes dos quais 622 de Agronomia, 145 de Computação, 213 Engenharia Ambiental e Energias Renováveis, 106 de Engenharia Cartográfica e de Agrimensura, 373 de Engenharia Florestal, 197 de Engenharia de Pesca, 355 de Medicina Veterinária, 182 de Zootecnia e 186 Sistemas de Informação.

Essa pesquisa possui uma abordagem qualitativa, utilizando-se de questionário fechado para coleta de dados. Para evitar a indução nos resultados, por parte dos pesquisadores, os questionários aplicados para o corpo discente da UFRA foram conduzidos sem nenhuma instrução prévia (CARVALHO; RODRIGUES, 2015). Ressalta-se que simultaneamente à coleta de dados foram realizadas observações in loco quanto a distribuição de lixeiras seletivas no campus.

O questionário foi composto por 20 perguntas fechadas e de fácil compreensão, porém foram aproveitadas no estudo apenas 13 perguntas, por ilustrarem melhor o objetivo da pesquisa. As questões foram desenvolvidas com base em análises bibliográficas e levantamentos de estudos de caso realizados na área da pesquisa que orientassem o embasamento teórico e metodológico do trabalho e preparassem para a posterior pesquisa de campo oferecendo dados e conceitos sobre a área de gestão dos resíduos sólidos mais especificamente da 
coleta seletiva (CAJAIBA; SANTOS, 2014; QUEIROZ; PEDRINI, 2014; BELUQUE et al., 2015).

A escolha do questionário ocorreu pela objetividade das perguntas, o que facilitou na tabulação das respostas e ajudou a obter os dados estatísticos com maior precisão. Além disso, vale ressaltar que o anonimato dos informantes foi preservado. Com a intenção de não provocar interferências nas respostas dos estudantes, os questionários foram respondidos sem nenhuma explicação teórica sobre o assunto pesquisado.

A delimitação da amostra populacional representativa (Tabela 1), foi realizada a partir do número de todos os alunos regularmente matriculados em 2016 no campus de Belém da UFRA. Assim foi definido o número populacional com base em Miot (2011) para uma amostra com tamanho conhecido e grau de confiança de 95\%.

TABELA 1. Cursos desenvolvidos pela Universidade Federal da Amazônia, no campus de Belém, seus respectivos números de estudantes regularmente matriculados em 2016 e o número amostral para cada curso (margem de confiança de 95\%).

\begin{tabular}{l|c|c}
\hline Cursos & $\begin{array}{c}\text { Alunos } \\
\text { matriculados }\end{array}$ & Amostra entrevistada \\
\hline Agronomia (AG) & 622 & 90 \\
\hline Licenciatura da Computação (LC) & 145 & 40 \\
\hline Engenharia Ambiental (EA) & 213 & 25 \\
\hline Engenharia cartográfica (EC) & 106 & 20 \\
\hline Engenharia de pesca (EP) & 197 & 30 \\
\hline Engenharia florestal (EF) & 373 & 49 \\
\hline Medicina veterinária (MV) & 355 & 25 \\
\hline Sistema de informação (SI) & 186 & 26 \\
\hline Zootecnia (ZO) & 182 & 30 \\
\hline Total & $\mathbf{2 3 7 9}$ & $\mathbf{3 3 5}$ \\
\hline
\end{tabular}

\section{RESULTADOS E DISCUSSÃO}

A comunidade acadêmica da Universidade Federal Rural da Amazônia, no campus de Belém, em quase a totalidade tem consciência do que se trata a coleta seletiva dos resíduos sólidos urbanos (97,3\% - Tabela 2).

TABELA 2. Questões e respostas de acordo com curso de graduação da Universidade Federal Rural da Amazônia, campus de Belém. Onde AG é o curso de Agronomia, EF, Engenharia Floresta, EA, Engenharia Ambiental, EC, Engenharia Cartográfica, EP, Engenharia de Pesca, LC, Licenciatura da Computação, MV, Medicina Veterinária, SI, Sistema de Informação e ZO, Zoologia.

\begin{tabular}{l|c|c|c|c|c|c|c|c|c|c}
\hline $\begin{array}{l}\text { Perguntas / } \\
\text { Respostas }\end{array}$ & AG & EF & EA & EC & EP & LC & MV & SI & ZO & Geral \\
\hline 01. Você sabe o que é coleta seletiva? \\
\hline Não & $0 \%$ & $0 \%$ & $0 \%$ & $0 \%$ & $3 \%$ & $20 \%$ & $2 \%$ & $8 \%$ & $0 \%$ & $\mathbf{2 \%}$ \\
\hline Sim & $100 \%$ & $100 \%$ & $100 \%$ & $100 \%$ & $97 \%$ & $80 \%$ & $98 \%$ & $92 \%$ & $100 \%$ & $\mathbf{9 7 \%}$ \\
\hline 02. Você sabe relacionar & tipo resíduo e as cores das lixeiras seletivas? \\
\hline Não & $6 \%$ & $5 \%$ & $0 \%$ & $4 \%$ & $3 \%$ & $25 \%$ & $10 \%$ & $19 \%$ & $16 \%$ & $\mathbf{8} \%$ \\
\hline Sim & $94 \%$ & $95 \%$ & $100 \%$ & $96 \%$ & $97 \%$ & $75 \%$ & $90 \%$ & $81 \%$ & $84 \%$ & $\mathbf{9 1 \%}$ \\
\hline 03. Quantas lixeiras seletivas você já encontrou no campus? \\
\hline 1 a 2 & $34 \%$ & $43 \%$ & $47 \%$ & $48 \%$ & $63 \%$ & $80 \%$ & $33 \%$ & $42 \%$ & $64 \%$ & $\mathbf{4 5 \%}$ \\
\hline 3 a 4 & $41 \%$ & $35 \%$ & $33 \%$ & $28 \%$ & $20 \%$ & $15 \%$ & $35 \%$ & $38 \%$ & $20 \%$ & $\mathbf{3 3 \%}$ \\
\hline 5 a 6 & $14 \%$ & $18 \%$ & $13 \%$ & $12 \%$ & $0 \%$ & $5 \%$ & $14 \%$ & $0 \%$ & $0 \%$ & $\mathbf{1 0 \%}$ \\
\hline Acima de 7 & $6 \%$ & $5 \%$ & $7 \%$ & $8 \%$ & $0 \%$ & $0 \%$ & $4 \%$ & $4 \%$ & $16 \%$ & $\mathbf{5} \%$ \\
\hline
\end{tabular}




\begin{tabular}{|c|c|c|c|c|c|c|c|c|c|c|}
\hline $\begin{array}{l}\text { Perguntas / } \\
\text { Respostas }\end{array}$ & AG & EF & EA & EC & EP & LC & MV & SI & $\mathbf{Z O}$ & Geral \\
\hline Nenhum & $3 \%$ & $0 \%$ & $0 \%$ & $4 \%$ & $17 \%$ & $0 \%$ & $14 \%$ & $15 \%$ & $0 \%$ & $6 \%$ \\
\hline \multicolumn{11}{|c|}{ 04. Você sabe identificar quais resíduos NÃO são recicláveis? } \\
\hline Não & $20 \%$ & $18 \%$ & $3 \%$ & $8 \%$ & $17 \%$ & $25 \%$ & $22 \%$ & $35 \%$ & $16 \%$ & $18 \%$ \\
\hline Sim & $80 \%$ & $82 \%$ & $97 \%$ & $92 \%$ & $83 \%$ & $75 \%$ & $78 \%$ & $65 \%$ & $84 \%$ & \\
\hline \multicolumn{11}{|c|}{ 05. Você sabe o que é o programa Coleta Seletiva Solidária? } \\
\hline Não & $77 \%$ & $93 \%$ & $70 \%$ & $92 \%$ & $83 \%$ & $85 \%$ & $90 \%$ & $88 \%$ & $84 \%$ & $83 \%$ \\
\hline Sim & $23 \%$ & $8 \%$ & $30 \%$ & $8 \%$ & $17 \%$ & $15 \%$ & $10 \%$ & $12 \%$ & $16 \%$ & \\
\hline \multicolumn{11}{|c|}{ Imente acondiciona seus resíduos? } \\
\hline Comum & $61 \%$ & $53 \%$ & $43 \%$ & $72 \%$ & $93 \%$ & $75 \%$ & $59 \%$ & $64 \%$ & $72 \%$ & $54 \%$ \\
\hline Seletiva & $31 \%$ & $43 \%$ & $47 \%$ & $24 \%$ & $7 \%$ & $20 \%$ & $35 \%$ & $32 \%$ & $24 \%$ & $0 \%$ \\
\hline Ambas & $8 \%$ & $5 \%$ & $10 \%$ & $4 \%$ & $0 \%$ & $5 \%$ & $6 \%$ & $4 \%$ & $4 \%$ & $6 \%$ \\
\hline \multicolumn{11}{|c|}{ 07. O número de lixeiras para coleta seletiva do campus é suficiente para atender a demanda? } \\
\hline Não & $49 \%$ & $68 \%$ & $77 \%$ & $48 \%$ & $80 \%$ & $65 \%$ & $73 \%$ & $38 \%$ & $80 \%$ & $62 \%$ \\
\hline & $29 \%$ & $25 \%$ & $10 \%$ & $4 \%$ & $13 \%$ & $25 \%$ & $18 \%$ & $35 \%$ & $12 \%$ & \\
\hline & $22 \%$ & $5 \%$ & $10 \%$ & $36 \%$ & & $10 \%$ & $8 \%$ & $23 \%$ & $4 \%$ & $5 \%$ \\
\hline Suficiente & $0 \%$ & $3 \%$ & $3 \%$ & $12 \%$ & $0 \%$ & $0 \%$ & $0 \%$ & $4 \%$ & $4 \%$ & \\
\hline \multicolumn{11}{|c|}{$\begin{array}{l}\text { 08. A distribuição no campus das lixeiras seletivas facilita o descarte dos resíduos nas } \\
\text { mesmas? }\end{array}$} \\
\hline Não & $41 \%$ & $38 \%$ & $63 \%$ & $36 \%$ & $73 \%$ & $63 \%$ & $63 \%$ & $54 \%$ & $52 \%$ & $51 \%$ \\
\hline Sim & $59 \%$ & $63 \%$ & $37 \%$ & $64 \%$ & $23 \%$ & $37 \%$ & $37 \%$ & $46 \%$ & $48 \%$ & $48 \%$ \\
\hline \multicolumn{11}{|c|}{$\begin{array}{l}\text { 09. A coleta seletiva na UFRA é importante para garantir um ambiente com qualidade para } \\
\text { gerações futuras? }\end{array}$} \\
\hline Importante & $31 \%$ & $33 \%$ & $13 \%$ & $36 \%$ & $40 \%$ & $40 \%$ & $16 \%$ & $35 \%$ & $32 \%$ & $30 \%$ \\
\hline Muito & $50 \%$ & $51 \%$ & $77 \%$ & $56 \%$ & $47 \%$ & $55 \%$ & $69 \%$ & $54 \%$ & $48 \%$ & $56 \%$ \\
\hline Não & $4 \%$ & & $3 \%$ & $0 \%$ & $3 \%$ & $5 \%$ & $4 \%$ & $8 \%$ & $4 \%$ & $4 \%$ \\
\hline Pouc & $6 \%$ & $8 \%$ & $3 \%$ & $0 \%$ & $7 \%$ & $0 \%$ & $4 \%$ & $0 \%$ & $8 \%$ & $4 \%$ \\
\hline Razoável & $9 \%$ & $5 \%$ & $3 \%$ & $8 \%$ & $3 \%$ & $0 \%$ & $6 \%$ & $4 \%$ & $8 \%$ & $6 \%$ \\
\hline \multicolumn{11}{|c|}{ 10. Você acha que o programa de coleta seletiva na UFRA é eficiente? } \\
\hline Eficiente & $6 \%$ & $3 \%$ & $3 \%$ & $8 \%$ & $0 \%$ & $5 \%$ & $4 \%$ & $4 \%$ & $4 \%$ & $4 \%$ \\
\hline Não & $22 \%$ & $38 \%$ & $60 \%$ & $16 \%$ & $40 \%$ & $30 \%$ & $35 \%$ & $27 \%$ & $44 \%$ & $33 \%$ \\
\hline Pouco & $32 \%$ & $33 \%$ & $23 \%$ & $16 \%$ & $33 \%$ & $25 \%$ & $35 \%$ & $38 \%$ & $20 \%$ & $30 \%$ \\
\hline Razoável & $40 \%$ & $28 \%$ & $13 \%$ & $60 \%$ & $27 \%$ & $40 \%$ & $27 \%$ & $31 \%$ & $32 \%$ & $33 \%$ \\
\hline \multicolumn{11}{|c|}{$\begin{array}{l}\text { 11. Você já identificou alguma ação de sensibilização aos alunos quanto a coleta seletiva no } \\
\text { campus? }\end{array}$} \\
\hline Não & $98 \%$ & $93 \%$ & $97 \%$ & $96 \%$ & $100 \%$ & $95 \%$ & $100 \%$ & $100 \%$ & $100 \%$ & $98 \%$ \\
\hline Sim & $2 \%$ & $8 \%$ & $3 \%$ & $4 \%$ & $0 \%$ & $5 \%$ & $0 \%$ & $0 \%$ & $0 \%$ & $2 \%$ \\
\hline
\end{tabular}

12. Se a UFRA possuísse parceria com cooperativas de reciclagem, haveria mais esforço de sua parte em dispor seus resíduos em lixeiras seletivas?

\begin{tabular}{l|c|c|c|c|c|c|c|c|c|c}
\hline Não & $9 \%$ & $10 \%$ & $17 \%$ & $12 \%$ & $7 \%$ & $10 \%$ & $8 \%$ & $12 \%$ & $8 \%$ & $\mathbf{1 0 \%}$ \\
\hline Sim & $91 \%$ & $90 \%$ & $83 \%$ & $88 \%$ & $93 \%$ & $90 \%$ & $92 \%$ & $88 \%$ & $92 \%$ & $\mathbf{9 0 \%}$ \\
\hline 13. Você tem interesse em participar de um programa de coleta seletiva voluntário? \\
\hline Não participaria & $41 \%$ & $29 \%$ & $10 \%$ & $36 \%$ & $31 \%$ & $35 \%$ & $41 \%$ & $62 \%$ & $28 \%$ & $\mathbf{3 6 \%}$ \\
\hline Participaria & $59 \%$ & $71 \%$ & $90 \%$ & $64 \%$ & $69 \%$ & $65 \%$ & $59 \%$ & $38 \%$ & $72 \%$ & $\mathbf{6 4 \%}$ \\
\hline
\end{tabular}

Os cursos de Licenciatura em Computação e Sistema de Informação foram os cursos com maior proporção de alunos que desconhecem a temática referente a coleta seletiva, cerca de 10 a $20 \%$ dos discentes. Isso certamente ocorre devido a distância desses cursos das temáticas ambientais. Esse quadro pode ser revertido com atividades sobre educação ambiental, na possibilidade de estimular nos discentes percepções e representações de um ambiente sustentável, com o olhar mais crítico sobre a problemática dos resíduos sólidos urbanos (SILVA et al., 2015; BALDIN; FRIDRICH, 2016). 
O graduando em Licenciatura em computação pela UFRA terá atuação na docência em educação básica no ensino de informática. Nesse contexto que surge a importância de agregar a interdisciplinaridade com matérias relacionadas ao meio ambiente na estrutura curricular desses cursos, visto que a educação ambiental pode ser aplicada em todos os espaços de aprendizagem e estar presente no currículo de todas as disciplinas (REIGOTA, 2007). Essa estratégia visa contribuir com a reflexão crítica e sensibilização dos estudantes sobre os valores ambientais (BESCORAVAINE et al., 2016).

Com relação a compreensão dos discentes em relacionar o tipo de resíduos com a respectiva cor da lixeira seletiva, percebeu-se que a maioria dos alunos sabe distinguir e condicionar corretamente seu resíduo nas lixeiras seletivas (90,7\%). No entanto, os cursos de Licenciatura em Computação (25\%), de Sistema de Informação (19\%), de Zootecnia (16\%) e de Medicina Veterinária (10\%) foram os cursos que apresentaram maior proporção de alunos que não conseguem associar a o material do resíduo com a cor do recipiente de descarte, mesmo grande parte dos alunos alegaram ter conhecimento sobre o conceito de coleta seletiva.

Quanto aos alunos que sabem discernir os resíduos recicláveis e os não recicláveis, notou-se que a proporção reduziu para $80,2 \%$ (Tabela 2). O curso de Engenharia Ambiental teve a maior representatividade de alunos que sabem discernir os materiais recicláveis e não recicláveis ( $97 \%)$, isso certamente é atribuído ao maior direcionamento desse curso em relação ao meio ambiente e pela inserção de disciplinas voltadas para a gestão dos resíduos sólidos na grade curricular.

A maioria dos estudantes da UFRA não sabem o que significa o programa Coleta Seletiva Solidária (83\%). Grande parte dos discentes em todos os nove cursos de graduação alegaram não ter conhecimento sobre o programa, inclusive o de Engenharia Ambiental (70\%). Quase a totalidade dos alunos de Engenharia Florestal (93\%) e de Engenharia da Computação (92\%) desconhecem esse assunto. A falta de conhecimento pode ser atribuída devido a universidade em questão ainda não ter aderido ao programa de coleta seletiva solidária.

Observou-se que quando se trata de tópicos específicos, como relacionar o tipo de resíduo gerado com a cor do recipiente para ser condicionado ou da finalidade do Programa de Coleta Seletiva Solidária, a proporção de alunos que desconhecem esses eixos aumentou entre $6 \%$ a $81 \%$ com relação ao número de entrevistados que desconhecem o conceito de coleta seletiva em âmbito geral. Tais resultados tornam evidente o desafio da educação ambiental em amadurecer o conhecimento dos graduandos nessa esfera, para que os mesmos assumam a responsabilidade social diante da problemática que envolve resíduos sólidos (BESCOROVAINE et al., 2016).

No que tange ao número de lixeiras seletivas identificadas pelos discentes entrevistados no campus, cerca de $63 \%$ afirmaram ter encontrado somente entre uma a duas lixeiras seletivas (Figura 1). Entretanto, notou-se grande disparidade entre todos os cursos, sendo que os graduandos de Zootecnia foram os que mais encontraram lixeiras seletivas, $16 \%$ dos alunos encontraram mais de sete lixeiras seletivas no campus, enquanto que os discentes que menos se depararam com lixeiras de coleta seletiva foram os de Engenharia de Pesca. 


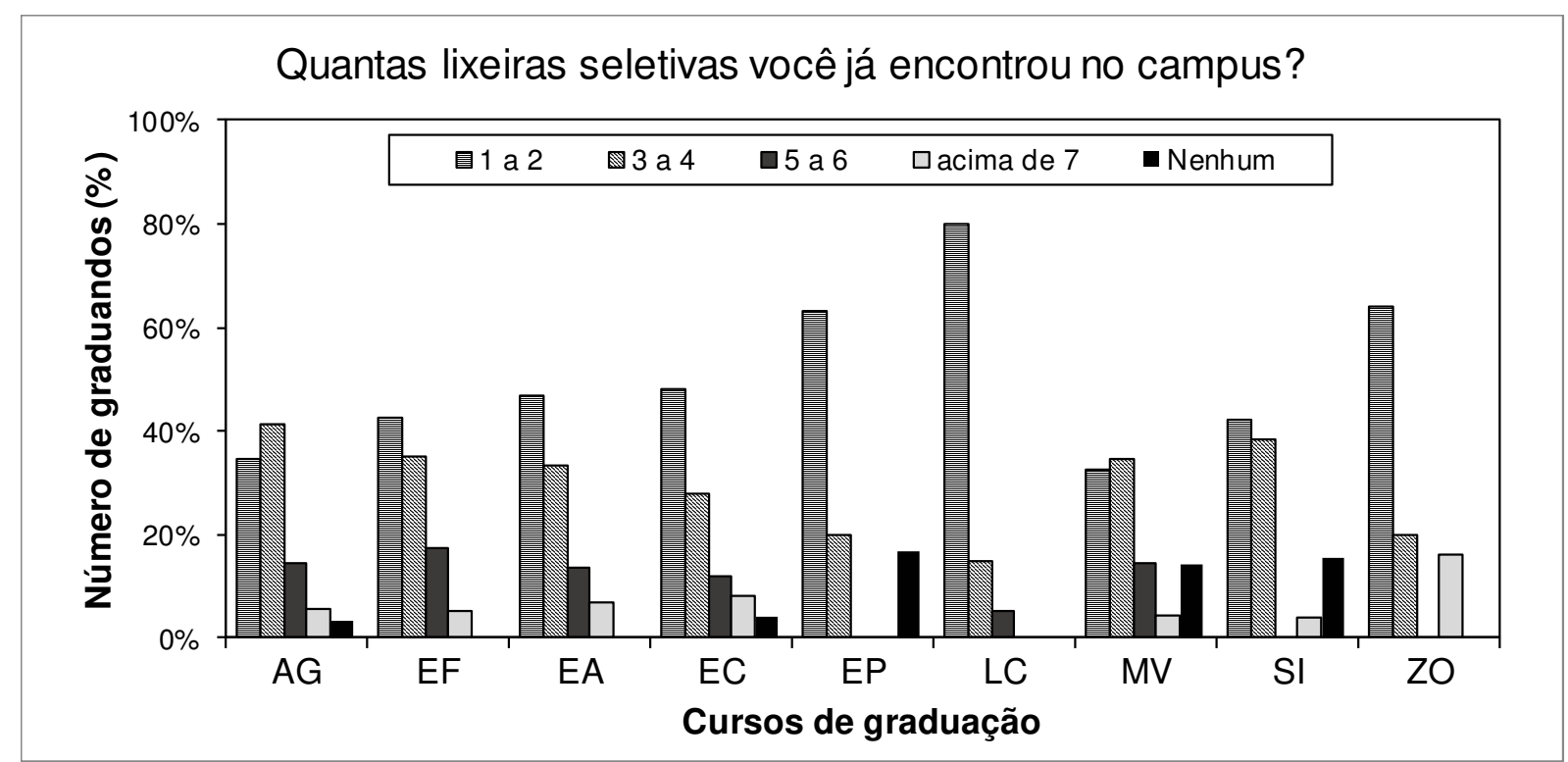

FIGURA 1. Número de lixeiras seletivas encontradas no campus de Belém na Universidade Federal Rural da Amazônia por discentes de cada curso de graduação. Onde AG é o curso de Agronomia; EF, Engenharia Floresta; EA, Engenharia Ambiental; EC, Engenharia Cartográfica; EP, Engenharia de Pesca; LC, Licenciatura da Computação; MV, Medicina Veterinária; SI, Sistema de Informação e ZO, Zoologia. Fonte: Autores.

A suficiência quanto ao número de lixeiras seletivas distribuídas no campus para atender a demanda de descarte foi classificada pelos entrevistados, predominantemente, como insuficiente (62\% - Tabela 2$)$. Em média, cada prédio do campus de Belém da UFRA comporta somente um conjunto de lixeiras seletivas (com recipiente para descarte de papel, plástico, metal e resíduo orgânico), de um total de 21 conjuntos contabilizados em todo o campus.

O principal local de condicionamento dos resíduos sólidos gerados pelos discentes da UFRA são as lixeiras comuns (63\%), embora $30 \%$ condicione preferencialmente em lixeiras seletivas e $0,05 \%$, em qualquer uma das duas. Isso ocorre devido a maior disponibilidade de lixeiras comuns no campus. De acordo com Brothers et al. (1994), a proximidade de container para a coleta específica de papel reciclado em um prédio administrativo aumentou a eficiência do aglomerado em $84 \%$ a $98 \%$ em relação ao peso sem essa intervenção.

Na pergunta "A distribuição no campus das lixeiras seletivas facilita o descarte dos resíduos nas mesmas", $51 \%$ dos discentes alegaram que não facilita e $48 \%$ afirmaram que sim. A disposição das lixeiras seletivas em locais estratégicos, principalmente em áreas de maior fluxo de alunos, em conjuntos com intervenções informativas como placas indicativas, implicará no aumento significativo no descarte adequadamente dos resíduos (LUDWING et al., 1998). Essas intervenções auxiliarão a disseminar o comportamento pró-ambiental nos estudantes da UFRA, com ações voltadas para sustentabilidade ambiental (LEMOS et al., 2016).

Apenas $4 \%$ dos discentes entrevistados classificaram o programa de coleta seletiva como eficiente (Tabela 2 ), 33\% classificou como razoável, 30\% como pouco e 33\% como ineficiente. Com relação aos cursos de graduação da UFRA, observouse que a maioria dos alunos de Engenharia Ambiental (60\%) consideraram que o programa de coleta seletiva na universidade é ineficiente (Figura 2). Supõe-se que devido a grade curricular ser bem próxima das questões ambientais, a maioria dos alunos apresentaram mais propriedades para classificar a eficiência deste programa. 


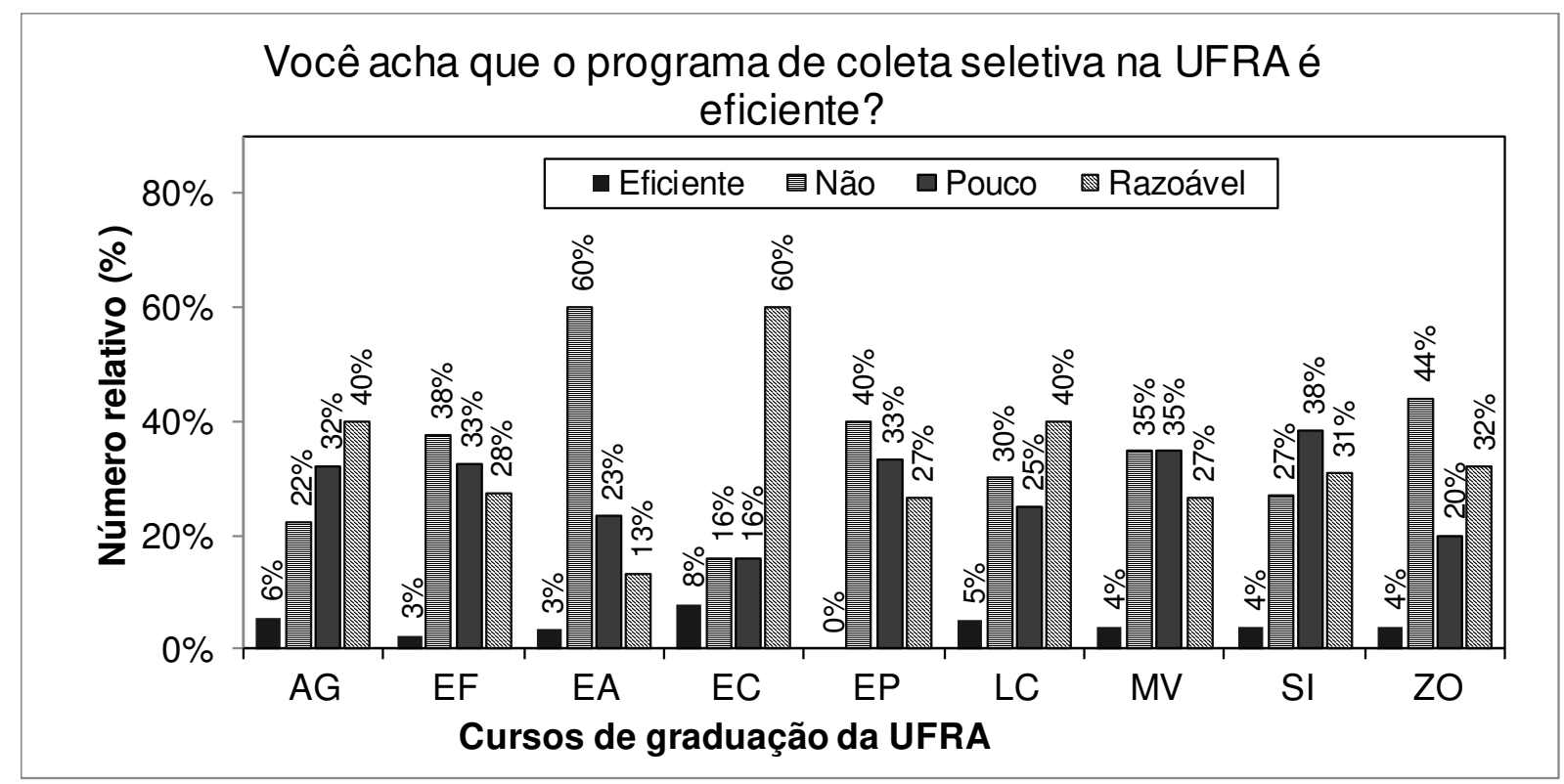

FIGURA 2. Classificação quanto a eficiência do programa de coleta seletiva na Universidade Federal Rural da Amazônia por curso de graduação. Onde AG é o curso de Agronomia; EF, Engenharia Floresta; EA, Engenharia Ambiental; EC, Engenharia Cartográfica; EP, Engenharia de Pesca; LC, Licenciatura da Computação; MV, Medicina Veterinária; SI, Sistema de Informação e ZO, Zoologia. Fonte: Autores.

Nenhum dos alunos de Engenharia de Pesca remete ao programa de coleta seletiva como eficiente $(0 \%)$. Embora poucos desse grupo de alunos desconheçam do que se trata a coleta seletiva (4\%), observou-se que a maioria se depararam somente com apenas uma ou duas lixeiras seletivas no campus, o que pode justificar essa classificação.

Cerca de $86 \%$ dos graduandos associam a coleta seletiva com a sustentabilidade ambiental, na perspectiva de garantir um ambiente com qualidade para as gerações futuras. Um grupo minoritário de $8 \%$, alegaram que a coleta seletiva é irrelevante ou pouco relevante para manter a qualidade para gerações futuras. A coleta seletiva contribui para o reaproveitamento de resíduos que a priori não terá valor algum, diminuindo no montante descartado em lixões e aterro sanitários, com isso reduzirá impactos ambientais, sociais e de saúde que envolve a destinação inadequada dos resíduos (CORREA, 2012; PASCHOALIN FILHO et al., 2014; FRANCO; MINÉU, 2015).

Quase a totalidade dos discentes entrevistados (98\%) alegaram que não identificaram ações que sensibilizassem a comunidade estudantil quanto a coleta seletiva. A sensibilização direcionada para a responsabilidade compartilhada desse grupo social é de suma importância na cadeia de reciclagem e reaproveitamento dos resíduos sólidos, pois a segregação mal realizada nas fontes geradoras implicará na ineficiência em toda a cadeia da gestão dos resíduos sólidos (BERNARDES; COLLARES, 2016).

Sobre a disposição em segregar corretamente os resíduos gerados pela comunidade acadêmica, caso a universidade formalizasse parceria com cooperativas para coleta desse material, grande parte dos alunos alegaram que colaborariam com a coleta seletiva (90\%) e uma pequena parcela de $10 \%$ dos alunos não cooperaria. Entretanto, Paschoalin Filho et al. (2014), diagnosticaram 
que no município de São Paulo, poucos moradores aderiram cooperar com a coleta seletiva, o que implicou na recuperação de apenas $1,6 \%$ de material reciclável em vista do volume gerado. De acordo com Leme (2009), a falta de hábito e a escassez de programas de coleta seletiva são os principais fatores que desestimulam os indivíduos a segregarem os resíduos gerados corretamente. Para que esse cenário não seja recorrente na UFRA, torna-se necessário a intervenção de várias medidas em conjunto, tais como ações de sensibilização quanto à problemática e benefícios que a coleta seletiva, formalização com cooperativas, inserção de placas indicativas, entre outras (LEMOS et al., 2016).

Ao questionar sobre o interesse dos discentes em participar voluntariamente de um programa de coleta seletiva, cerca de 64\% afirmaram positivamente. Bescoravaine et al. (2016), identificaram que grande parcela dos universitários da Instituição de Ensino Superior de Maringá possui interesse em temáticas ambientais, no entanto, uma ínfima parcela já participou de programas ligados a essa temática.

\section{CONCLUSÕES}

Conclui-se a partir da aplicação dos questionários que a percepção dos discentes da UFRA ainda é limitada no aspecto geral do conceito de coleta seletiva, o que implica na falta de sensibilidade sobre seu papel diante dos impactos gerados pelo inadequado condicionamento dos resíduos.

Embora, a grande maioria dos discentes tenham interesse em mudar seus hábitos na segregação de seus resíduos, torna-se de suma importância intervenções que auxiliarão a disseminar esse comportamento pró-ambiental na universidade. Tais como atividades práticas, palestras e ações voltadas para a coleta seletiva, bem como formalizar parcerias com cooperativas de reciclagem, além de melhor equipar os prédios da universidade com maior número de lixeiras seletivas.

Além disso, a percepção da comunidade acadêmica da UFRA, campus Belém, pode ser melhorada por meio de atividades de educação ambiental e inclusão de matérias relacionadas ao meio ambiente na estrutura curricular de todos os cursos da instituição. Dessa forma, futuramente a universidade terá alunos mais instruídos e preocupados com a situação tanto da coleta seletiva como do meio ambiente dentro e fora da universidade. Simples ações como o incentivo ao aprendizado ambiental podem formar futuros cidadãos mais responsáveis com 0 meio ambiente.

\section{REFERÊNCIAS}

BALDIN, N.; FRIDRICH, G. A. Percepções socioambientais sobre o rio Iguaçu por crianças de escolas de União da Vitória (PR) e Porto União (SC): Lições de educação ambiental. In: DIAS, L. S.; LEAL, A. C.; CARPI JUNIOR, S. (Orgs.). Educação Ambiental: conceitos, metodologia e práticas. Tupã: ANAP, p. 68-98, 2016.

BELUQUE, A.; BOSCO, T. C. D.; PRATES, K. V. M. C.; BONFANTE, M C.; SUDO, C. H. Percepções sobre a coleta seletiva solidária na UTFPR campus Londrina. Revista Brasileira de Educação Ambiental. São Paulo, v. 10, n. 1, p. 146-163, 2015.

BERNARDES, L. F.; COLLARES, A. C. Z. B. Avaliação da percepção ambiental da população a fim de contribuir para a reimplantação da coleta seletiva no município de São João Batista do Glória (MG). Ciência et Praxis, v. 9, n. 17, p. 25-30, 2016. 
Disponível em: <http://revista.uemg.br/index.php/praxys/article/view/2268/1222>

BESCOROVAINE, W. F.; SILVA, G. A.; SILVA, J. R.; MILANI, L. H. P.; MILANI, R. G. Comportamento pró-ambiental e descarte de resíduos sólidos por estudantes de arquitetura: apontamentos para a educação ambiental. Revista Geográfica Acadêmica, v. $10, \quad$ n. 2, p. 105-115, 2016. Disponível em: <http://dx.doi.org/10.18227/1678-7226rga.v10i2.3861> doi: 10.18227/16787226rga.v10i2.3861

BESEN, G. R.; RIBEIRO, H.; GÜNTHER, W. M. R.; JACOBI, P. R. Coleta seletiva na região metropolitana de São Paulo: impactos da Política Nacional de Resíduos Sólidos. Ambiente \& Sociedade. São Paulo, v. XVII, n. 3, p. 259-278, 2014. Disponível em: < http://dx.doi.org/10.1590/S1414-753X2014000300015>. doi: 10.1590/S1414-753X2014000300015

BRASIL. Lei n. 12.305 - Política Nacional de Resíduos Sólidos. Brasília, 2010. Disponível em: <http://www.planalto.gov.br/ccivil_03/_ato2007 2010/2010/lei/l12305.htm >. Acesso em: 15 de agosto de 2016.

BRASIL. Ministério do Meio Ambiente. Decreto $n^{\circ} 5.940$, de 25 de outubro de 2006. Institui a separação dos resíduos recicláveis descartados pelos órgãos e entidades da administração pública federal direta e indireta, na fonte geradora, e a sua destinação às associações e cooperativas dos catadores de materiais recicláveis, e dá outras providências. Disponível em: <http://www.planalto.gov.br/ccivil_03/_Ato2004-2006/2006/Decreto/D5940.htm>. Acesso em: 15 ago. 2016.

BROTHERS, K. J.; KRANTZ, P. J.; MCCLANNAHAN, L. E. Office paper recycling: a function of container proximity. Journal os Applied Behavior Analysis, v. 27, n. 1, p. 153-160, 1994.1 Disponível em: <https://www.ncbi.nlm.nih.gov/pmc/articles/PMC1297784/> doi: 10.1901/jaba.1994.27-153

CAJAIBA, R. L.; SANTOS, E. M. Conhecimento dos alunos do ensino fundamental sobre coleta seletiva: um estudo de caso no município de Uruará-PA. Enciclopédia

Biosfera, v. 10, n. 18, 2014. Disponível em: < http://www.conhecer.org.br/enciclop/2014a/CIENCIAS\%20HUMANAS/conhecimento. pdf>

CARVALHO, A. P.; RODRIGUES, M. A. N. Percepção ambiental de moradores no entorno do açude Soledade no estado da Paraíba. Revista Eletrônica em Gestão, Educação e Tecnologia Ambiental, v. 19, n. 3, p. 25-35, 2015. Disponível em: <https://periodicos.ufsm.br/reget/article/viewFile/17986/pdf>doi:105902/2236117017 986

CORREA, É. K.; AVANCINI, A. R.; MONCKS, R. B.; PAZ, M. F. CORRÊA, L. B. Utilização de ferramentas de educação ambiental na implantação do programa de coleta seletiva no centro de engenharias da universidade federal de pelotas. Revista Eletrônica do Mestrado em Educação Ambiental. v. 29. 2012. Disponível em: < https://www.seer.furg.br/remea/article/view/2966>

EIGENHEER, E. M.; FERREIRA, J. A. Três décadas de coleta seletiva em São Francisco (Niterói/RJ): lições e perspectivas. Revista Engenharia Sanitária e 
Ambiental, v. 20, n. 4, p. 677-684, 2015. Disponível em: <http://dx.doi.org/10.1590/S1413-41522015020040132994>. doi: 10.1590/S141341522015020040132994

FRANCO, C. C.; MINÉU, H. F. S. O programa de coleta seletiva em Ituiutaba: análise de sua implantação e resultados. Boletim de Geografia, v. 33, n. 1, p. 81, 2015. em: http://periodicos.uem.br/ojs/index.php/BolGeogr/article/view/21184> doi: 10.4025/bolgeogr.v33i1.21184

LEITE, J. K. S.; ARRUDA, S. G. B.; SILVA, L. J. A.; CAMPOS, L. A. A. Envolvimento sustentável: o UFPE na praça incentivando a educação ambiental. Revista Brasileira de Educação Ambiental. São Paulo, V. 10, n.1, p. 301-315, 2015. Disponível em:

http://sbecotur.org.br/revbea/index.php/revbea/article/view/4605/2995>.

LEME, S. M. Comportamento da população urbana no manejo dos resíduos sólidos domiciliares em Aquidauana - MS. Geografia, v. 18, n. 1, p. 157-192, 2009. Disponível em:

http://www.uel.br/revistas/uel/index.php/geografia/article/view/2392>.

LEMOS, L. H. A.; CARVALHO, J. F.; GURGEL, P. R. H. A análise do comportamento como subsídio possível à gestão dos resíduos sólidos. Interespaço, v. 2, n. 7, p. 195-208, 2016. Disponível em: < http://dx.doi.org/10.18764/2446-6549.v2n7p195208> doi: 10.18764/2446-6549.v2n7p195-208

LUDWIG, T. D.; GRAY, T. W.; ROWELL, A. Increasing recycling in academic buildings: A systematic replication. Journal of applied behavior analysis, v. $31, n$. 4, p. 683-686, 1998. Disponível em: <https://www.ncbi.nlm.nih.gov/pmc/articles/PMC1284165/> doi:10.1901/jaba.1998.31-683

MIOT, H. A. Tamanho da amostra em estudos clínicos e experimentais. Jornal Vascular Brasileiro, v. 10, n. 4, 2011. Disponível em: < http://dx.doi.org/10.1590/S1677-54492011000400001>. doi: 10.1590/S167754492011000400001

OLIVEIRA, T. B.; GALVÃO JUNIOR, A. C. Planejamento municipal na gestão dos resíduos sólidos urbanos e na organização da coleta seletiva. Revista Engenharia Sanitária e Ambiental, v. 21, n. 1, p. 55-64, 2016. Disponível em: < http://dx.doi.org/10.1590/S1413-41520201600100155929>. doi: 10.1590/S141341520201600100155929

PASCHOALIN FILHO, J. A.; SILVEIRA, F. F.; LUZ, E. G.; OLIVEIRA, R. B. Comparação entre as massas de resíduos sólidos urbanos coletadas na cidade de São Paulo por meio de coleta seletiva e domiciliar. Revista de Gestão Ambiental e Sustentabilidade, v. 3, n. 3, p. 19-33, 2014. Disponível em: < http://www.revistageas.org.br/ojs/index.php/geas/article/view/208>.

QUEIROZ, A. P. B.; PEDRINI, A. G. Percepção ambiental de moradores de condomínios no município de Niterói, estado Rio de Janeiro, Brasil sobre resíduos sólidos urbanos associados a sua coleta seletiva. Revista Eletrônica do Mestrado 
em Educação Ambiental. v. 31, n. 2, p. 5-21, 2014. Disponível em: < https://www.seer.furg.br/remea/article/view/4558>.

REIGOTA, M. O Estado da Arte da Pesquisa em Educação Ambiental no Brasil. Pesquisa em Educação Ambiental, v. 2, n. 1, p. 33-66, 2007. Disponível em: < https://www.revistas.usp.br/pea/article/view/30017/31904>.

SILVA, G. N.; SANTOS, C. K. S.; SANTOS, M. J. B. A.; SANTOS, T. A. A educação ambiental formal como ferramenta de sensibilização para a coleta seletiva na EMEF Olga Benário, em Aracaju/SE. Revista Sergipana de Educação Ambiental, v. 1, n. 2 ,

p. 55-77, 2015.

Disponível

em:

$<$ https://seer.ufs.br/index.php/revisea/article/view/4444>.

SOUZA, V. O. Educação ambiental na efetivação de práticas ecológicas: um estudo de caso sobre práticas ecológicas e coleta seletiva na Universidade Estadual da Paraíba. Revista Brasileira de Educação Ambiental. São Paulo, V. 9, n.2, p. 364375, 2014. Disponível em:

http://www.sbecotur.org.br/revbea/index.php/revbea/article/view/3613>. 